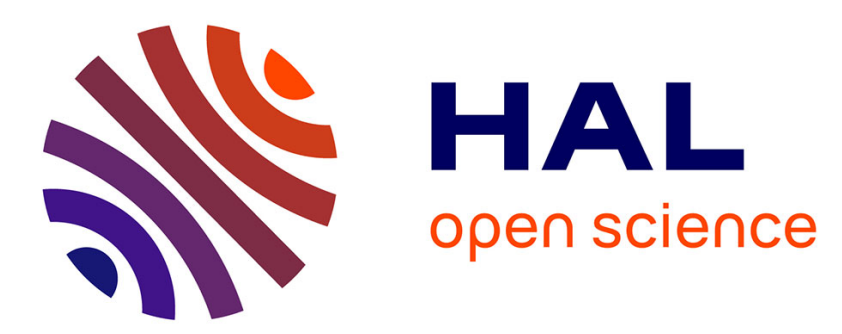

\title{
Silicon-Based Optoelectronic Tongue for Label-Free and Nonspecific Recognition of Vegetable Oils
}

B. V. Oliinyk, K. Isaieva, A. I. Manilov, T. Nychyporuk, A. Geloen, F. Joffre, V. A. Skryshevsky, S. V. Litvinenko, V. Lysenko

\section{- To cite this version:}

B. V. Oliinyk, K. Isaieva, A. I. Manilov, T. Nychyporuk, A. Geloen, et al.. Silicon-Based Optoelectronic Tongue for Label-Free and Nonspecific Recognition of Vegetable Oils. ACS Omega, 2020, 5 (11), pp.5638-5642. 10.1021/acsomega.9b03196 . hal-02901851

\section{HAL Id: hal-02901851 \\ https://hal.science/hal-02901851}

Submitted on 3 Dec 2020

HAL is a multi-disciplinary open access archive for the deposit and dissemination of scientific research documents, whether they are published or not. The documents may come from teaching and research institutions in France or abroad, or from public or private research centers.
L'archive ouverte pluridisciplinaire HAL, est destinée au dépôt et à la diffusion de documents scientifiques de niveau recherche, publiés ou non, émanant des établissements d'enseignement et de recherche français ou étrangers, des laboratoires publics ou privés. 


\title{
Silicon-Based Optoelectronic Tongue for Label-Free and Nonspecific Recognition of Vegetable Oils
}

\author{
Bohdan V. Oliinyk, Karyna Isaieva, Anton I. Manilov,* Tetyana Nychyporuk, Alain Geloen, \\ Florent Joffre, Valeriy A. Skryshevsky, Sergii V. Litvinenko, and Vladimir Lysenko
}

Cite This: ACS Omega 2020, 5, 5638-5642

Read Online

\section{ACCESS \\ Wll Metrics \& More \\ Article Recommendations \\ Supporting Information}

ABSTRACT: A special electronic tongue system based on photoelectric measurements on $\mathrm{Si}-$ $\mathrm{Si} / \mathrm{SiN}_{X}$ sensitive structures is reported. The sensing approach is based on measuring of minority carrier lifetime in silicon-based substrates using microwave-detected photoconductance decay. This inexpensive and environmentally friendly combinatorial electronic sensing platform is able to create characteristic electronic fingerprints of liquids, detect, and recognize them. In particular, an application of the optoelectronic tongue for recognition of vegetable oils and their mixtures is described.

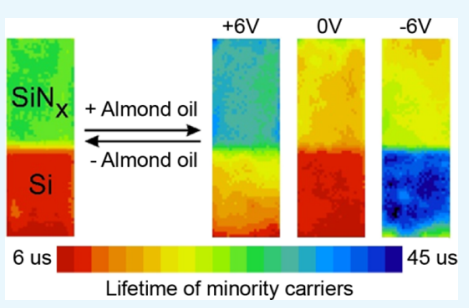

\section{INTRODUCTION}

Development and improvement of analytical methods for assuring quality and authenticity of vegetable oils are very important research axes in the food field. In particular, the objectives of empowering detection and fostering prevention of oil fraud are considerably supported by European Union's research and innovation programs. ${ }^{1}$ On the basis of the expanding market for vegetable oils, their authenticity has become an important subject from both commercial and health point of view. ${ }^{2,3}$ Among all vegetable oils, the extra virgin olive oil is known to have the highest economical value. ${ }^{4}$ At the same time, rapeseed, soyabean, and palm oils are the cheapest ones available in the market and can be used to 'bulk-out' more expensive products. Thus, the analytic methods resolving the problem of oil adulteration as well as determining origin, quality, and oxidative stability of oils are continuously under intensive development.

The main instrumental approaches of oil analysis include different methods of chromatography and mass spectrometry, as well as their combination, such as: high-resolution gas chromatography, high-performance liquid chromatography, supercritical fluid chromatography, stable isotope ratio mass spectrometry, chemical ionization mass spectrometry, and so forth. $^{5-7}$ In addition, nuclear magnetic resonance spectroscopy, $^{8}$ differential scanning calorimetry, ${ }^{9}$ Fourier transform infrared spectroscopy, Raman spectroscopy, ${ }^{10-12}$ fluorescence spectroscopy, ${ }^{13,14}$ and DNA-analysis instruments ${ }^{12,15}$ are also widely applied for investigation of vegetable oils.

Most of the conventional methods cited above consist of time-consuming, expensive, and complex set-ups and technological procedures. Some of them use toxic chemicals and solvents. Therefore, development of innovative, cheap, and efficient sensor-based concepts is of primary importance. ${ }^{16}$ In order to improve efficiency of the oil detection, novel sensing components are investigated, for instance, microwave sensing interdigitated electrodes ${ }^{17}$ or a fiber optic long period gratingbased sensor. ${ }^{18}$ Nevertheless, the most promising results are obtained with multisensor platforms exploiting the concept of electronic nose and tongue. For example, electronic noses based on metal oxide semiconductors, ${ }^{19-21}$ conducting polymers, ${ }^{22-24}$ quartz crystal microbalances, ${ }^{25,26}$ and detectors of surface acoustic wave ${ }^{27,28}$ were applied for differentiation of vegetable oils. As for the electronic tongues, they are mainly based on voltammetric measurements in electrochemical cells $^{29-32}$ or potentiometric sensor arrays. ${ }^{33-37}$

Our research team has recently developed a special electronic tongue system based on optoelectronic measurements with use of silicon wafers. ${ }^{38}$ In particular, we have shown its successful application for the recognition of water and spirits. This kind of electronic tongue is an inexpensive and environmental friendly combinatorial electronic sensing platform that is able to record characteristic electronic fingerprints of liquids resulted from their interaction with either naturally aged or specifically treated silicon substrates. In this letter, we report an application of the silicon-based optoelectronic tongue for recognition of vegetable oils and their mixtures.

\section{RESULTS AND DISCUSSION}

Our sensing approach is based on measuring of minority carrier lifetime in silicon by using a microwave-detected photoconductance decay as shown in Figure 1. A pulse of infrared (IR) laser (904 nm) generates free electron-hole

Received: September 28, 2019

Accepted: February 24, 2020

Published: March 12, 2020 


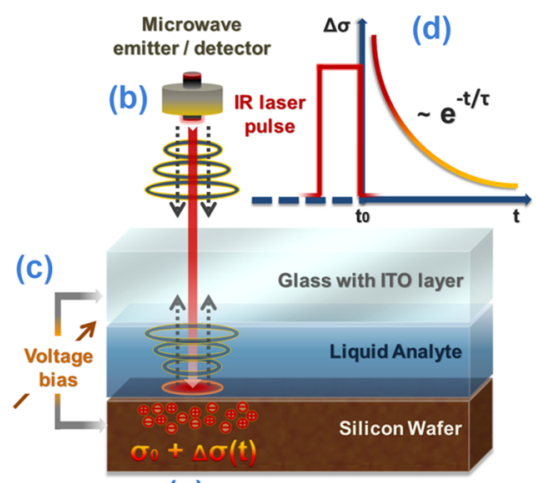

(a)

Figure 1. Basic physical principles used in the optoelectronic tongue: (a) generation of free electron-hole pairs near the silicon surface under absorption of IR laser pulse; (b) dependence of microwave reflectivity on concentration of the free charge carriers; (c) modulation of surface band bending by analyte-silicon interaction and applied voltage bias; (d) time-resolved photoconductivity decay due to recombination of the generated electron-hole pairs as a function of surface band bending.

pairs under illuminated area close to the front surface of a silicon wafer (penetration depth of the laser radiation in silicon is about $30 \mu \mathrm{m})$. Because the free electrons and holes recombine, their concentration and, consequently, conductivity of the silicon sample decreases exponentially in time after the action of the exciting light pulse. The decaying conductivity can be monitored by detecting microwave reflectivity ensured by the photogenerated free charge carriers as a function of time. The measured reflectivity decay is fitted with an exponential curve, and the obtained time constant $\left(\tau_{\text {meas }}\right)$ corresponds to the effective lifetime of the photocreated charge carriers in the given position of the silicon sample. Changing the illuminated zone of the studied sample allows the creation of its $2 \mathrm{D}$ map in terms of the lifetime values $\tau_{\text {meas, }}$ which depend on silicon parameters and its surface chemistry. If a silicon sample is put in an intimate contact with a chemical substance (e.g., liquid), a new $\tau_{\text {meas }}$ map induced by the substance molecules interacting electronically with the silicon surface will be obtained. Thus, one can establish a correlation between a surface distribution of the $\tau_{\text {meas }}$ values obtained for the given substance/silicon interface and chemical composition of the liquid substance.

To increase reliability of liquid recognition, one can additionally record a set of $\tau_{\text {meas }}$ maps by polarizing the liquid/silicon interface as it is schematically shown in Figure 1. Indeed, continuous tuning of the difference of electric potentials $V_{\mathrm{b}}$ applied to the interface will ensure modulation of the electronic bands bending in the near-surface region of the silicon substrate. The voltage dependent band bending leads to refilling of interface electronic states and significant voltage-induced modulation of the lifetime maps formed by the studied liquid sample onto the silicon surface.

A typical Si-based structure used in this work is schematically represented in Figure 2. A half of the structure was covered with an ultrathin $\operatorname{SiN}_{X}$ layer $(10-15 \mathrm{~nm})$. The $\operatorname{SiN}_{X}$ films are well-known to be widely used in the industrial silicon solar cell fabrication process. ${ }^{39}$ Indeed, chemical composition of the $\mathrm{SiN}_{X}$ layers ensures an excellent electronic passivation of various defects localized at the surface of bulk silicon substrates. $^{40}$ As a result, lifetime of charge carriers photogenerated in $\mathrm{Si}$ substrates covered with a $\mathrm{SiN}_{X}$ layer increases

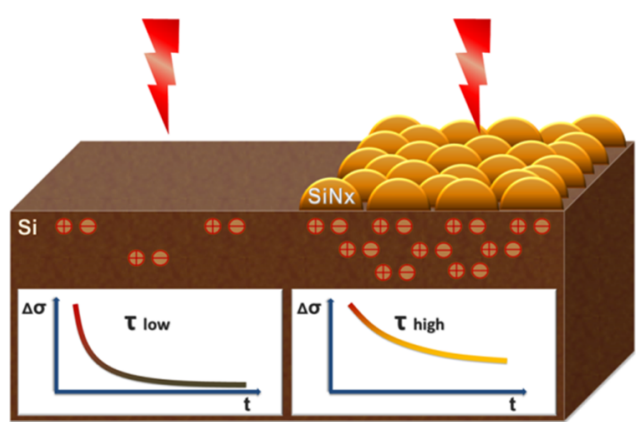

Figure 2. Typical $\mathrm{Si}-\mathrm{Si} / \mathrm{SiN}_{X}$ sensitive structure used in this work. A half of the structure is covered with an ultrathin (non continuous) $\mathrm{SiN}_{X}$ layer passivating the silicon surface and characterized by increased lifetimes of photogenerated charge carriers.

significantly. One can compare $2 \mathrm{D}$ maps of the $\tau_{\text {meas }}$ values obtained for the $\mathrm{Si}$ samples covered with $\mathrm{SiN}_{X}$ layers deposited at various silane-to-ammonia gas flow ratios $R=\mathrm{SiH}_{4} / \mathrm{NH}_{3}$. As shown in Figure 3A, the higher the $R$ value is, the higher the

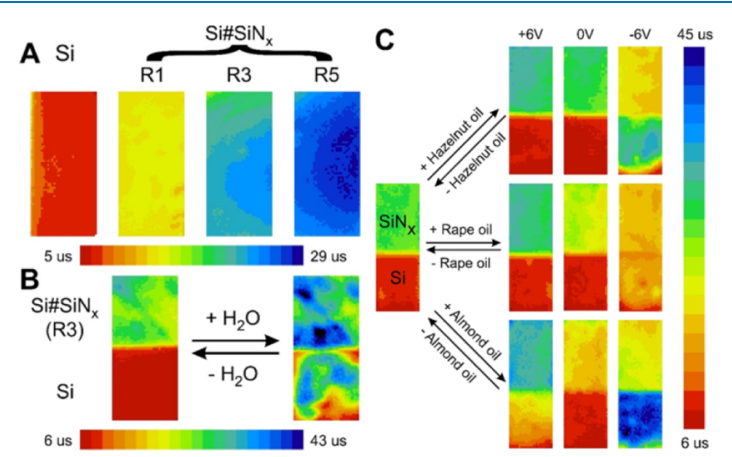

Figure 3. (A) Characteristic lifetimes of a bare Si substrate and $\mathrm{Si}$ substrates covered by $\mathrm{SiN}_{X}$ films obtained at various silane-toammonia gas flow ratios $(R)$. (B) Impact of water molecules on the $2 \mathrm{D} \tau_{\text {meas }}$ map of a $\mathrm{Si}-\mathrm{Si} / \mathrm{SiN}_{X}$ substrate. (C) $2 \mathrm{D} \tau_{\text {meas }}$ maps of a $\mathrm{Si}-$ $\mathrm{Si} / \mathrm{SiN}_{X}$ substrate put in contact with almond, rape, and hazelnut oils at different polarizing voltages $V_{\mathrm{b}}$.

corresponding lifetimes $\left(\tau_{\text {meas }}\right)$ values are. In particular, the $\tau_{\text {meas }}$ value (about $30 \mu \mathrm{s}$ ) obtained for the Si-rich $\mathrm{SiN}_{X}$ layers deposited at R5 is much higher than the $\tau_{\text {meas }}$ value for a bare Si surface $(5 \mu \mathrm{s})$, for example.

In our work, extremely low deposition time (about 10-20 s) of the $\mathrm{SiN}_{X}$ layers was used in order to avoid complete capping of the silicon surface by a continuous film of silicon nitride (as sketched in Figure 2). This is especially important to allow the studied liquids to get at least partial access to the Si surface semipassivated by the $\mathrm{SiN}_{X}$ films. Indeed, being able to penetrate through the numerous subnanometer pores, grooves and/or gaps present in the $\mathrm{SiN}_{X}$ ultrathin layers, the studied liquid will modulate significantly the initial lifetime values measured in air. As one can see in Figure 3B, water molecules influence strongly the $\tau_{\text {meas }}$ map of a Si sample having two regions: (i) the bare $\mathrm{Si}$ surface and (ii) the $\mathrm{SiN}_{X}$ ultrathin layer deposited on the $\mathrm{Si}$ substrate at $\mathrm{R} 3$. In general, the lifetime values are considerably enhanced for the both regions exposed to water. After water removal, the $2 \mathrm{D}$ distribution of the $\tau_{\text {meas }}$ values was completely reset.

To demonstrate high applicative potential of the optoelectronic tongue for the oil recognition purpose, a set of various oil samples has been used. The most representative $2 \mathrm{D} \tau_{\text {meas }}$ 
maps of the photoelectric fingerprints created by almond, rape, and hazelnut oils on the $\mathrm{Si}-\mathrm{Si} / \mathrm{SiN}_{X}$ sensitive structures at 0 and $\pm 6 \mathrm{~V}$ of the voltage bias $V_{\mathrm{b}}$ are shown in Figure 3C. Here, positive sign of the voltage corresponds to accumulative band bending of the p-type silicon wafer. As one can see, the most important difference between the $\tau_{\text {meas }}$ maps formed by the studied oils corresponds to $V_{\mathrm{b}}=-6 \mathrm{~V}$. Thus, one could use this $V_{\mathrm{b}}$ value for rapid qualitative recognition of the tested oils. At this value of the polarizing voltage $(-6 \mathrm{~V})$, the most pronounced electronically passivating impact on the silicon surface is provoked by almond oil, while distribution of the $\tau_{\text {meas }}$ values $(17-22 \mu \mathrm{s})$ in the $\mathrm{Si} / \mathrm{SiN}_{X}$ region remains almost insensitive to the oil samples. In particular, almost no difference between the $\tau_{\text {meas }}$ values for both $\mathrm{Si}$ and $\mathrm{Si} / \mathrm{SiN}_{X}$ regions can be observed for the case of the rape oil polarized at $V_{\mathrm{b}}=-6 \mathrm{~V}$. As for the inhomogeneity of lifetime distribution over the sample surface, which was observed for water, is almost negligible for the all the studied oil samples. Indeed, a slight distribution of the lifetimes within a given zone is much less than the changes of the lifetimes for various oils exposed to various voltages.

At the same time, the most significant voltage-induced evolution of the recorded $\tau_{\text {meas }}$ maps corresponds to the interface between the $\mathrm{Si}-\mathrm{Si} / \mathrm{SiN}_{X}$ substrates and almond oil. The evolution kinetics is extremely slow. Once a voltage value is set, the corresponding voltage-induced changes of a $\tau_{\text {meas }}$ map can take up to $30 \mathrm{~min}$. Finally, it is worth to note complete reversibility of the initial $2 \mathrm{D} \tau_{\text {meas }}$ maps in air after the washing out of the oil samples. Indeed, as one can see in Figure S1 (shown in the Supporting Information), the $\tau_{\text {meas }}$ maps recorded in air after each exposition of the $\mathrm{Si}-\mathrm{Si} / \mathrm{SiN}_{X}$ substrate to an oil sample are identical and correspond to the map of the original substrate before its first use.

To ensure a high discrimination capability level of the proposed sensing system, the data can be visualized in more illustratable manner. In our work, principal component analysis (PCA) method was applied. ${ }^{41}$ This multivariate analysis approach enables to find a set of linearly uncorrelated variables so that the first has maximum variance, and each next variable is orthogonal to the previous and has maximum possible variance with this constraint. This method is widely used for dimension reduction because most of the information is concentrated in the first components and commonly employed in various combinatorial platforms for discrimination purposes. ${ }^{42-44}$ As a result, Figure $4 \mathrm{~A}$ shows a plot of three first principal components (with corresponding scores of $26.8 \%$ for the first principal component, $22.6 \%$ for the second principal component, and $14.7 \%$ for the third one) containing clouds of points for each of the tested oils. In particular, because the distance between the points reflects their nonsimilarity, clear clustering of the data illustrates a perfect degree of discrimination capability of our analytical system to recognize among the studied oils. With only two kinds of regions (bare Si and $\mathrm{Si}$ covered with $\mathrm{SiN}_{X}$ islands) and three values of the polarizing voltage $V_{\mathrm{b}}(0$ and $\pm 6 \mathrm{~V})$, we are already able to observe a significant degree of discrimination between the different oils. Natural small variation of the lifetimes within a single zone is taken into account and reflected by distance between the points at the PCA diagram in Figure 4A for each oil sample. Because of the distance between the points within the same cloud is less than the distances between the clouds, the recognition of the oil samples can be evaluated as a reliable one.
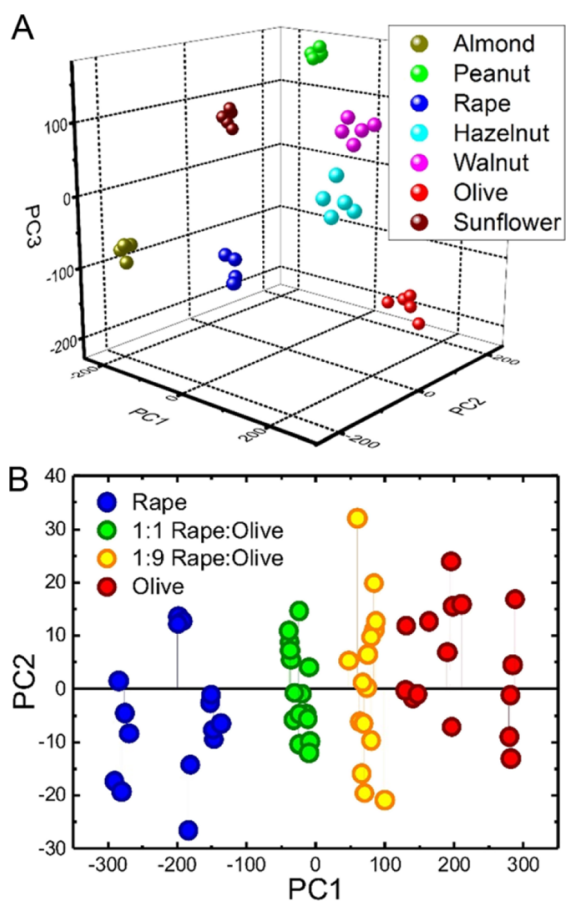

Figure 4. (A) 3D PCA plot corresponding to the electronic fingerprints of the tested oils formed on the $\mathrm{Si}-\mathrm{Si} / \mathrm{SiN}_{X}$ substrate at different polarizing voltages $V_{\mathrm{b}}$. (B) 2D PCA plot corresponding to the electronic fingerprints of olive and rape oils as well as their mixtures. The units of the principal components on the axes are microseconds.

Virgin olive oil possessing unique qualities is highly appreciated by consumers because of its exceptional nutritional, medicinal, cosmetic, and even ceremonial value. As a result, it is one of the most expensive and also one of the most adulterated food products. In particular, its adulteration with low-grade olive oils or cheaper vegetable oils (e.g., such as rape oil) could potentially be very profitable for sellers or raw material suppliers and may yield large economic profits. Thus, authentication of virgin olive oils has become an interesting subject from both commercial and health perspectives. Figure $4 \mathrm{~B}$ demonstrates the ability of the optoelectronic tongue based on the $\mathrm{Si}-\mathrm{Si} / \mathrm{SiN}_{X}$ sensitive structures described in this letter to recognize mixtures of olive and rape oils. Indeed, Figure $4 \mathrm{~B}$ shows a plot of two first-principal components (with corresponding scores of $67.7 \%$ for the first principal component and $16.6 \%$ for the second principal component) containing points for initial pure olive and rape oils as well as their mixtures (all samples measured three times). The first mixture (1:9) was selected as a minimal (from commercial view point) amount of rapeseed added to olive oil. The second mixture $(1: 1)$ is intermediate between the pure rapeseed and olive oils. As one can see, the cloud corresponding to the olive oil with $10 \%$ of rape oil is clearly different from the cloud related to the sample of the pure olive oil. It is worth noting that the cloud corresponding to the $50 \%$ mixture of the oil samples is localized on the PCA plot in the middle between the clouds corresponding to the pure oils.

The described approach is based on a holistic measurement approach. Indeed, a complex and simultaneous impact of all oil components forms the sensor signal in each zone. In other words, all the molecules constituting the given oil physically impact the electronic surface states initially governed by the 
surface chemistry of each zone (bare c-Si or $\mathrm{SiN}_{X}$ film) and by bias voltage. Unlike other known sensing systems, specific sensitive materials and components are not necessary to be used. Moreover, certain chemical indicators are not determined, such as peroxide value, concentration of additives, etc. Even so, our optoelectronic tongue is able to distinguish different classes of oils and their mixtures using PCA.

\section{CONCLUSIONS}

In conclusion, the optoelectronic tongue based on the $\mathrm{Si}-\mathrm{Si}$ / $\mathrm{SiN}_{X}$ substrates can be efficiently applied for a label-free and nonspecific recognition of vegetable oils. In particular, the lifetime of photogenerated charge carriers is confirmed to be an extremely efficient physical parameter ensuring high sensitivity of silicon-based structures to play a role of an electronic screen reflecting the complex physicochemical interaction between the bare or partially covered silicon surface and the studied chemical substance. This specific kind of electronic tongues is an inexpensive and environmental friendly combinatorial electronic-sensing platform that is able to create characteristic electronic fingerprints of liquids, detect, and recognize them.

\section{ASSOCIATED CONTENT}

\section{(s) Supporting Information}

The Supporting Information is available free of charge at https://pubs.acs.org/doi/10.1021/acsomega.9b03196.

Fabrication of the $\mathrm{Si}-\mathrm{Si} / \mathrm{SiN}_{X}$ samples, cleaning of the Si$\mathrm{Si} / \mathrm{SiN}_{X}$ samples, and mathematical treatment of the obtained data (PDF)

\section{AUTHOR INFORMATION}

\section{Corresponding Author}

Anton I. Manilov - Institute of High Technologies, Taras Shevchenko National University of Kyiv, 01033 Kyiv, Ukraine; Corporation Science Park Taras Shevchenko University of Kyiv, 01033 Kyiv, Ukraine; (1) orcid.org/0000-0003-2225-2754; Email: anmanilov@univ.kiev.ua

\section{Authors}

Bohdan V. Oliinyk - Institute of Analytical Sciences (ISA), UMR CNRS 5280, UCBL, University of Lyon, 69100 Villeurbanne, France; OlisensTech, 69006 Lyon, France; (1) orcid.org/0000-0002-1895-3980

Karyna Isaieva - IADI, Universite de Lorraine, INSERM U1254, Nancy F-54000, France

Tetyana Nychyporuk - Nanotechnology Institute of Lyon (INL), UMR CNRS 5270, INSA de Lyon, University of Lyon, 69621 Lyon, France

Alain Geloen - CarMeN Laboratory, INRA UMR1397, INSERM U1060, INSA de Lyon, IMBL, University of Lyon, 69621 Lyon, France

Florent Joffre - Institut des Corps Gras (ITERG), 33610 Canéjan, France

Valeriy A. Skryshevsky - Institute of High Technologies, Taras Shevchenko National University of Kyiv, 01033 Kyiv, Ukraine; Corporation Science Park Taras Shevchenko University of Kyiv, 01033 Kyiv, Ukraine

Sergii V. Litvinenko - Institute of High Technologies, Taras Shevchenko National University of Kyiv, 01033 Kyiv, Ukraine; Corporation Science Park Taras Shevchenko University of Kyiv, 01033 Kyiv, Ukraine
Vladimir Lysenko - Light-Matter Institute (ILM), UMR

CNRS 5306, University of Lyon (UCBL), 69622 Lyon, France

Complete contact information is available at:

https://pubs.acs.org/10.1021/acsomega.9b03196

\section{Notes}

The authors declare no competing financial interest.

\section{ACKNOWLEDGMENTS}

This work was financially supported by the Carnot LISA Institute in frame of the IRSOLIP project: "Identification et reconnaissance des solutions lipidiques par imagerie". The authors acknowledge Dr. Mykola Isaiev (LEMTA, Université de Lorraine) for fruitful discussions.

\section{REFERENCES}

(1) The OLEUM project http://www.oleumproject.eu (accessed Jan 31, 2020).

(2) Oils and Fats Authentication; Jee, M., Ed.; Chemistry and technology of oils and fats; Blackwell: Oxford, 2002.

(3) Gunstone, F. Chemistry of Oils and Fats: Sources, Composition, Properties and Uses; Wiley: Williston, 2009.

(4) Handbook of Olive Oil: Analysis and Properties, 2nd ed.; Aparicio, R., Harwood, J. L., Eds.; Springer: New York, NY, 2013.

(5) Aparicio, R.; Aparicio-Ruíz, R. Authentication of Vegetable Oils by Chromatographic Techniques. J. Chromatogr. A 2000, 881, 93104.

(6) Jakab, A.; Nagy, K.; Héberger, K.; Vékey, K.; Forgács, E. Differentiation of Vegetable Oils by Mass Spectrometry Combined with Statistical Analysis: Analysis of Oils by MS and Statistical Analysis. Rapid Commun. Mass Spectrom. 2002, 16, 2291-2297.

(7) Green, H. S.; Li, X.; De Pra, M.; Lovejoy, K. S.; Steiner, F.; Acworth, I. N.; Wang, S. C. A Rapid Method for the Detection of Extra Virgin Olive Oil Adulteration Using UHPLC-CAD Profiling of Triacylglycerols and PCA. Food Control 2020, 107, 106773.

(8) Hidalgo, F. J.; Zamora, R. Edible Oil Analysis by HighResolution Nuclear Magnetic Resonance Spectroscopy: Recent Advances and Future Perspectives. Trends Food Sci. Technol. 2003, 14, 499-506.

(9) Chiavaro, E.; Rodriguez-Estrada, M. T.; Barnaba, C.; Vittadini, E.; Cerretani, L.; Bendini, A. Differential Scanning Calorimetry: A Potential Tool for Discrimination of Olive Oil Commercial Categories. Anal. Chim. Acta 2008, 625, 215-226.

(10) Rohman, A.; Man, Y. B. C. Fourier Transform Infrared (FTIR) Spectroscopy for Analysis of Extra Virgin Olive Oil Adulterated with Palm Oil. Food Res. Int. 2010, 43, 886-892.

(11) Baeten, V.; Hourant, P.; Morales, M. T.; Aparicio, R. Oil and Fat Classification by FT-Raman Spectroscopy. J. Agric. Food Chem. 1998, 46, 2638-2646.

(12) Meenu, M.; Cai, Q.; Xu, B. A Critical Review on Analytical Techniques to Detect Adulteration of Extra Virgin Olive Oil. Trends Food Sci. Technol. 2019, 91, 391-408.

(13) Sikorska, E.; Górecki, T.; Khmelinskii, I. V.; Sikorski, M.; Koziol, J. Classification of Edible Oils Using Synchronous Scanning Fluorescence Spectroscopy. Food Chem. 2005, 89, 217-225.

(14) González-Domínguez, R.; Sayago, A.; Morales, M. T.; Fernández-Recamales, A. Assessment of Virgin Olive Oil Adulteration by a Rapid Luminescent Method. Foods 2019, 8, 287.

(15) Bazakos, C.; Dulger, A. O.; Uncu, A. T.; Spaniolas, S.; Spano, T.; Kalaitzis, P. A SNP-Based PCR-RFLP Capillary Electrophoresis Analysis for the Identification of the Varietal Origin of Olive Oils. Food Chem. 2012, 134, 2411-2418.

(16) Valli, E.; Bendini, A.; Berardinelli, A.; Ragni, L.; Riccò, B.; Grossi, M.; Gallina Toschi, T. Rapid and Innovative Instrumental Approaches for Quality and Authenticity of Olive Oils: Innovative Approaches for Quality of Virgin Olive Oils. Eur. J. Lipid Sci. Technol. 2016, 118, 1601-1619. 
(17) Korostynska, O.; Blakey, R.; Mason, A.; Al-Shamma'a, A. Novel Method for Vegetable Oil Type Verification Based on Real-Time Microwave Sensing. Sens. Actuators, A 2013, 202, 211-216.

(18) Libish, T. M.; Bobby, M. C.; Linesh, J.; Mathew, S.; Pradeep, C.; Nampoori, V. P. N.; Biswas, P.; Bandyopadhyay, S.; Dasgupta, K.; Radhakrishnan, P. Detection of Adulteration in Virgin Olive Oil Using a Fiber Optic Long Period Grating Based Sensor. Laser Phys. 2013, 23, 045112 .

(19) González Martín, Y.; Cerrato Oliveros, M. C.; Pérez Pavón, J. L.; García Pinto, C.; Moreno Cordero, B. Electronic Nose Based on Metal Oxide Semiconductor Sensors and Pattern Recognition Techniques: Characterisation of Vegetable Oils. Anal. Chim. Acta 2001, 449, 69-80.

(20) García-González, D.; Aparicio, R. Detection of Defective Virgin Olive Oils by Metal-Oxide Sensors. Eur. Food Res. Technol. 2002, 215, 118-123.

(21) Hai, Z.; Wang, J. Electronic Nose and Data Analysis for Detection of Maize Oil Adulteration in Sesame Oil. Sens. Actuators, B 2006, 119, 449-455.

(22) Shen, N.; Moizuddin, S.; Wilson, L.; Duvick, S.; White, P.; Pollak, L. Relationship of Electronic Nose Analyses and Sensory Evaluation of Vegetable Oils during Storage. J. Am. Oil Chem. Soc. 2001, 78, 937-940.

(23) Aparicio, R.; Rocha, S. M.; Delgadillo, I.; Morales, M. T. Detection of Rancid Defect in Virgin Olive Oil by the Electronic Nose. J. Agric. Food Chem. 2000, 48, 853-860.

(24) Guadarrama, A.; Rodríguez-Méndez, M. L.; Sanz, C.; Ríos, J. L.; de Saja, J. A. Electronic Nose Based on Conducting Polymers for the Quality Control of the Olive Oil Aroma. Anal. Chim. Acta 2001, 432, 283-292.

(25) Escuderos, M. E.; Sánchez, S.; Jiménez, A. Virgin Olive Oil Sensory Evaluation by an Artificial Olfactory System, Based on Quartz Crystal Microbalance (QCM) Sensors. Sens. Actuators, B 2010, 147, $159-164$.

(26) Santonico, M.; Grasso, S.; Genova, F.; Zompanti, A.; Parente, F.; Pennazza, G. Unmasking of Olive Oil Adulteration Via a MultiSensor Platform. Sensors 2015, 15, 21660-21672.

(27) Biswas, S.; Heindselmen, K.; Wohltjen, H.; Staff, C. Differentiation of Vegetable Oils and Determination of Sunflower Oil Oxidation Using a Surface Acoustic Wave Sensing Device. Food Control 2004, 15, 19-26.

(28) Marina, A. M.; Che Man, Y. B.; Amin, I. Use of the SAW Sensor Electronic Nose for Detecting the Adulteration of Virgin Coconut Oil with RBD Palm Kernel Olein. J. Am. Oil Chem. Soc. 2010, 87, 263-270.

(29) Apetrei, C.; Rodríguez-Méndez, M. L.; de Saja, J. A. Modified Carbon Paste Electrodes for Discrimination of Vegetable Oils. Sens. Actuators, B 2005, 111-112, 403-409.

(30) Oliveri, P.; Baldo, M. A.; Daniele, S.; Forina, M. Development of a Voltammetric Electronic Tongue for Discrimination of Edible Oils. Anal. Bioanal. Chem. 2009, 395, 1135-1143.

(31) Men, H.; Chen, D.; Zhang, X.; Liu, J.; Ning, K. Data Fusion of Electronic Nose and Electronic Tongue for Detection of Mixed Edible-Oil. J. Sens. 2014, 2014, 1-7.

(32) Tsopelas, F.; Konstantopoulos, D.; Kakoulidou, A. T. Voltammetric Fingerprinting of Oils and Its Combination with Chemometrics for the Detection of Extra Virgin Olive Oil Adulteration. Anal. Chim. Acta 2018, 1015, 8-19.

(33) Tortora, L.; Stefanelli, M.; Mastroianni, M.; Lvova, L.; Di Natale, C.; D’Amico, A.; Filippini, D.; Lundström, I.; Paolesse, R. The Hyphenated CSPT-Potentiometric Analytical System: An Application for Vegetable Oil Quality Control. Sens. Actuators, B 2009, 142, 457463.

(34) Dias, L. G.; Fernandes, A.; Veloso, A. C. A.; Machado, A. A. S. C.; Pereira, J. A.; Peres, A. M. Single-Cultivar Extra Virgin Olive Oil Classification Using a Potentiometric Electronic Tongue. Food Chem. 2014, 160, 321-329.

(35) Souayah, F.; Rodrigues, N.; Veloso, A. C. A.; Dias, L. G.; Pereira, J. A.; Oueslati, S.; Peres, A. M. Discrimination of Olive Oil by
Cultivar, Geographical Origin and Quality Using Potentiometric Electronic Tongue Fingerprints. J. Am. Oil Chem. Soc. 2017, 94, 1417-1429.

(36) Semenov, V.; Volkov, S.; Khaydukova, M.; Fedorov, A.; Lisitsyna, I.; Kirsanov, D.; Legin, A. Determination of Three Quality Parameters in Vegetable Oils Using Potentiometric E-Tongue. J. Food Compos. Anal. 2019, 75, 75-80.

(37) Rodrigues, N.; Marx, Í. M. G.; Casal, S.; Dias, L. G.; Veloso, A. C. A.; Pereira, J. A.; Peres, A. M. Application of an Electronic Tongue as a Single-Run Tool for Olive Oils' Physicochemical and Sensory Simultaneous Assessment. Talanta 2019, 197, 363-373.

(38) Litvinenko, S. V.; Bielobrov, D.; Lysenko, V.; Nychyporuk, T.; Skryshevsky, V. A. Might Silicon Surface Be Used for Electronic Tongue Application? ACS Appl. Mater. Interfaces 2014, 6, 1844018444.

(39) Hahn, G.; Joos, S. State-of-the-Art Industrial Crystalline Silicon Solar Cells. Semiconductors and Semimetals; Elsevier, 2014; Vol. 90, pp $1-72$.

(40) Lelièvre, J.-F.; Fourmond, E.; Kaminski, A.; Palais, O.; Ballutaud, D.; Lemiti, M. Study of the Composition of Hydrogenated Silicon Nitride SiNx:H for Efficient Surface and Bulk Passivation of Silicon. Sol. Energy Mater. Sol. Cells 2009, 93, 1281-1289.

(41) Pearson, K. On lines and planes of closest fit to systems of points in space. London, Edinburgh Dublin Philos. Mag. J. Sci. 1901, 2, $559-572$.

(42) Kim, K. I.; Jung, K.; Kim, H. J. Face recognition using kernel principal component analysis. IEEE Signal Processing Letters 2002, 9, $40-42$.

(43) Yeung, K. Y.; Ruzzo, W. L. Principal component analysis for clustering gene expression data. Bioinformatics 2001, 17, 763-774.

(44) Zhu, K.; Chi, C.; Yu, Z.; Zhang, W.; Fan, M.; Li, K.; Zhang, Q. Extracting borehole strain precursors associated with the Lushan earthquake through principal component analysis. Annals of Geophysics 2018, 61, 447. 